that in California, as elsewhere along the Pacific rim, seismic risk (the product of hazard and vulnerability) is steadily increasing as population and infrastructure grow. On the Mojave segment of the San Andreas fault due north of Los Angeles, palaeoseismic studies have shown that the average time between major earthquakes over the past seventeen centuries has been about 130 years. The segment last ruptured in the great magnitude- 8 earthquake of 1857 . The clock is ticking.

Richard Sibson is in the Department of Geology, University of Otago, PO Box 56, Dunedin, New Zealand.

\section{Driving forces}

\section{John de la Mothe}

Physics and the Rise of Scientific Research in Canada. By Yves Gingras. McGill-Queens University Press: 1991. Pp.203. Canadian \$37.50, £33.20.

FAR too often, the development of scientific disciplines and institutions is portrayed as being the result of heroic efforts on the part of exceptional individuals. Far too often, the relationship that exists today between teaching and research is thought to be fully mature and at the end of some 'natural' evolutionary process. And far too often, the historical path taken to develop universities and research facilities is thought of in terms of the expression of science's 'will' on its social milieu rather than in terms of a more dynamic interaction between science and its sociopolitical milieu. Happily, in what is a superb example of descriptive ethnographic history of science, Yves Gingras has managed to avoid all of these popular tendencies and has provided readers with a fresh perspective on the transition of physics from a liberal art to a research profession.

To be sure, we are already quite well informed about the institutionalization of scientific research in countries with long-standing and well-established scientific traditions - such as the United Kingdom, the United States, France and Germany. But because of the very recent development of Canada's research system, Gingras's analysis is able to provide us with useful and subtle generalizations about the modern scientific enterprise itself - and not just in Canada.

The conceptual framework used to achieve this proceeds through essentially three phases. The first of these consists of the emergence of a research practice. In countries with rather young scientific traditions, such as Canada or Australia, this most frequently occurs through the importation of knowledge and techniques (such as through a series of apprenticeships in European laboratories). In countries with older scientific traditions, however, the emergence of new practices - or the development of new disciplines such as physics - can often be explained with reference to the institutionalization of an individual's or group's experiences (witness, for example, the emergence of organic chemistry around Justus von Liebig at Gussen in about 1840).

Once conditions for the emergence of a research practice have been established, the first representatives of this new practice can work to impose a view of the role or function of the university on the university, which, in turn, allows or takes into consideration the new research practices of the group. This promotes the long-term 'reproduction' of both the practice and the discipline. As Gingras argues, it is the second phase the institutionalization of research that is critical to the formation of all national scientific communities.

The final phase involves the formation of a social identity which is either based on discipline (for example, the creation of an association) or on profession (for example, through the formation of a corporation). By establishing official representatives for themselves, researchers acquire a social visibility and can thus defend not only their own interests but also those of their discipline. Clearly, the details of Gingras's welldocumented and briefly stated framework will be of principal interest to professional historians and sociologists of science. But it is also cast so gently over the bulk of this valuable study that its organizing power is always transparent. It is never obtrusive to the general reader, and it never detracts from the telling of an intricate 'story' about the establishment of research in Canada. Indeed, this story is simultaneously about many things, all of which are important. It is about the transition from teaching to research and research-based teaching; the securing of resources for research; the role of such institutions as the Royal Society of Canada and the National Research Council; the role of such vehicles as the Canadian Journal of Research; the importance of other disciplines and professions to the development of new practices; and it is also about the changing status of the research professions viz the style of government intervention. All of these stories are deftly told by Gingras.

As he states, "the status accorded research in the present-day university may give the impression that, along with teaching, the production of new knowledge has always been one of the essential functions of this institution." But this is not the case. During the second half of the nineteenth century, physics teaching in Canadian universities underwent important changes. From natural philosophy, which was taught to all students in the arts faculties and which required only the services of a professor trained in the traditional bachelor of arts model (which was then dominated by philosophy, Latin and classics), Gingras has documented the move to establish fullyfledged departments of physics where students could take temporary leave of their textbooks and be introduced to the techniques of early experimental physics. The major cause lying behind this transformation was the nineteenth-century demand for engineering education created by Canada's industrial development. The institutionalization of engineering education, as well as the development of medical faculties during the $1870 \mathrm{~s}$, thus created a growing need for science courses. The social outgrowth in demand directly supported the development of physics departments (and science departments in general) from the 1880 s onwards. By the 1890 s, a coterie of trained researchers had begun to appear and to find positions in Ontario, Quebec and across Canada, which in turn allowed them - and the country to be well prepared to contribute to the technological demands arising from the First World War. The external conditions fostered or at least channelled by the newly formed National Research Council, and coupled with the growing social importance of physics, helped to put in place - by 1930 - a stable national system of research in Canada.

Since that time, the transition of Canada's scientific capabilities has continued, shaped by the same forces that brought it into being in the first place. The stresses of interdisciplinary rivalry (for example between physics and engineering) for labour market share, of publication and of research funding in a steady state all continue to resonate even after the period of Gingras's historical analysis has ended. Thus the reader of this book is left with a tacit acceptance of the Gingras framework. Indeed, the reader is left with an articulate and broadly appealing book, which not only provides a general analysis of the driving forces behind the development of professional scientific research, but which also provides both a basis for future comparative studies as well as an extension into an era of a new profession — that of science policy itself.

John de la Mothe is at the J. F. Kennedy School of Government, Harvard University, Cambridge, Massachusetts 02138, USA and is a science adviser to the Science Council of Canada, 100 Metcalfe Street, Ottawa, Ontario KIP SMI, Canada. 